University of Wollongong

Research Online

Australian Institute for Innovative Materials -

Papers

Australian Institute for Innovative Materials

$1-1-2014$

The role of emissive charge transfer states in two polymer-fullerene organic photovoltaic blends: tuning charge photogeneration through the use of processing additives

Tracey M. Clarke

University of Wollongong, tclarke@uow.edu.au

Jeff Peet

Konarka Technologies

Christoph Lungenschmied

Konarka Technologies

Nicolas Drolet

Konarka Technologies

Xinhui Lu

Brookhaven National Laboratory

See next page for additional authors

Follow this and additional works at: https://ro.uow.edu.au/aiimpapers

Part of the Engineering Commons, and the Physical Sciences and Mathematics Commons

Research Online is the open access institutional repository for the University of Wollongong. For further information contact the UOW Library: research-pubs@uow.edu.au 


\title{
The role of emissive charge transfer states in two polymer-fullerene organic photovoltaic blends: tuning charge photogeneration through the use of processing additives
}

\begin{abstract}
The role of charge transfer (CT) states in organic photovoltaic systems has been debated in the recent literature. In this paper the device performances of two structurally analogous polymers PDTSiTTz (also known as KP115) and PCPDTTTz blended with PCBM are investigated, focusing on the effect the processing additive diiodooctane (DIO) has on morphology, charge photogeneration, and, in particular, the CT state characteristics. While DIO has a considerable beneficial effect for PCPDTTTZ:PCBM photovoltaic devices, negligible effects are observed for PDTSiTTZ:PCBM devices. An emissive CT state able to be quenched by DIO was observed for PCPDTTTz:PCBM, despite relatively small morphological changes. This is only the second instance of CT state quenching by a processing additive to be reported. Formation of an emissive CT state is therefore a loss pathway for PCPDTTTz:PCBM, which can be alleviated through the use of DIO to increase the proportion of CT states that dissociate into free charges. Conversely, the CT state of PDTSiTTZ:PCBM is weak and short-lived, with the DIO having little effect. The CT state dissociates more efficiently for this higher crystallinity system, leading to less evidence of emissive CT state recombination, and high charge photogeneration yields and device efficiencies.
\end{abstract}

\section{Keywords}

role, emissive, charge, transfer, states, processing, two, additives, polymer, fullerene, organic, photovoltaic, blends, tuning, photogeneration

Disciplines

Engineering | Physical Sciences and Mathematics

\section{Publication Details}

Clarke, T. M., Peet, J., Lungenschmied, C., Drolet, N., Lu, X., Ocko, B. M., Mozer, A. J. \& Loi, M. Antonietta. (2014). The role of emissive charge transfer states in two polymer-fullerene organic photovoltaic blends: tuning charge photogeneration through the use of processing additives. Journal of Materials Chemistry A, 2 (31), 12583-12593.

\section{Authors}

Tracey M. Clarke, Jeff Peet, Christoph Lungenschmied, Nicolas Drolet, Xinhui Lu, Benjamin M. Ocko, Attila Mozer, and Maria Antonietta Loi 
Cite this: DOI: 10.1039/xoxxooooox

Received ooth January 2012, Accepted ooth January 2012

DOI: $10.1039 / \times 0 x \times 00000 x$

www.rsc.org/

\section{The role of emissive charge transfer states in two polymer/fullerene organic photovoltaic blends: tuning charge photogeneration through the use of processing additives}

\author{
Tracey M. Clarke,,${ }^{\mathrm{a}, *}$ Jeff Peet, ${ }^{\mathrm{b}}$ Christoph Lungenschmied, ${ }^{\mathrm{b}}$ Nicolas Drolet, ${ }^{\mathrm{b}}$ \\ Xinhui Lu, ${ }^{\mathrm{c}}$ Benjamin M. Ocko, ${ }^{\mathrm{c}}$ Attila J. Mozer, ${ }^{\mathrm{a}}$ and Maria Antonietta Loi ${ }^{\mathrm{d}}$
}

\begin{abstract}
The role of charge transfer (CT) states in organic photovoltaic systems has been debated in the recent literature. In this paper the device performances of two structurally analogous polymers PDTSiTTz (also known as KP115) and PCPDTTTz blended with PCBM are investigated, focusing on the effect the processing additive diiodooctane (DIO) has on morphology, charge photogeneration, and, in particular, the CT state characteristics. While DIO has a considerable beneficial effect for PCPDTTTz:PCBM photovoltaic devices, negligible effects are observed for PDTSiTTz:PCBM devices. An emissive CT state able to be quenched by DIO was observed for PCPDTTTz:PCBM, despite relatively small morphological changes. This is only the second instance of CT state quenching by a processing additive to be reported. Formation of an emissive CT state is therefore a loss pathway for PCPDTTTz:PCBM, which can be alleviated through the use of DIO to increase the proportion of CT states that dissociate into free charges. Conversely, the CT state of PDTSiTTZ:PCBM is weak and short-lived, with the DIO having little effect. The CT state dissociates more efficiently for this higher crystallinity system, leading to little evidence of emissive CT state recombination, and high charge photogeneration yields and device efficiencies.
\end{abstract}

\section{Introduction}

Organic photovoltaic devices based on a polymer/fullerene bulk heterojunction have demonstrated exceptional increases in power conversion efficiencies in recent years. ${ }^{1,2}$ Numerous limiting factors have been identified in order to promote future increases in performance, such as poor charge transport, ${ }^{3,4}$ low dielectric constants and concomitant high coulomb binding energies, ${ }^{5}$ bimolecular and geminate recombination processes, 6 , 7 and active layer thickness limitations. ${ }^{8}$ In particular, the photophysics and energetics have received significant attention, principally since the observation of interfacial charge transfer (CT) states in organic photovoltaic blends. ${ }^{9-11}$

These CT states form an intermediate state between the photogenerated exciton and the fully separated charge carriers. ${ }^{6}$ The exact role of this CT state in charge carrier photogeneration and recombination has been much debated in the recent literature. For instance, it has been proposed that due to the energy offset of the donor and acceptor energy levels, initial exciton dissociation will create a CT state that is initially thermally 'hot'. 12 This 'hot' CT state can use the additional thermal energy to undergo dissociation into fully separated charge carriers. Alternatively, it can vibrationally relax and then undergo a variety of loss mechanisms, including radiative recombination back to the ground state. In this picture of CT state formation, this thermally-relaxed CT state forms a loss mechanism.

However, several reports have argued with this viewpoint. It has been proposed that the extent of CT state delocalisation ${ }^{13,14}$ promotes dissociation into free charges. Furthermore, it has been suggested that sub-bandgap excitation directly into the CT state manifold is capable of generating free charge carriers, implying that an excess driving force for charge separation is unnecessary for charge photogeneration. ${ }^{15-17}$ At the same time, the hot CT state picture has garnered support in the form of various time-resolved vibrational $^{18}$ and absorption spectroscopy ${ }^{19}$ results. Howard et al., ${ }^{20-22}$ amongst others, ${ }^{14,}$ 23-25 have shown for several polymer:fullerene systems that exciton dissociation creates two populations of charges: the formation of a CT state that constitutes a loss pathway via geminate recombination, and the direct generation of free charge carriers.

In some polymer:polymer and polymer:fullerene systems, this CT state is emissive. ${ }^{9,26-29}$ Emissive CT states are characterised 
by a broad, red-shifted long-lived photoluminescence (PL) that is present in the blend film but has no counterpart in either of the single component's PL spectra. One system in particular that has been extensively studied in terms of its CT state is PCPDTBT blended with PCBM ([6,6]-phenyl C61-butyric acid methyl ester). ${ }^{27,28,30}$

PCPDTBT:PCBM was also the first reported to display a processing additive effect. Peet et al. observed that photovoltaic devices of PCPDTBT:PCBM received a large boost in power conversion efficiency if the additive octanedithiol (ODT) was added to the solution during processing. ${ }^{31}$ Subsequent investigations revealed that this increase in efficiency was due to an improved phase separation and morphology, ${ }^{32}$ higher charge photogeneration yields, ${ }^{33}$ lower triplet yields, ${ }^{34}$ less geminate recombination, ${ }^{24,25,35}$ and higher charge carrier mobility. ${ }^{36}$ Interestingly, this additive had a further effect: it quenched the CT state emission of PCPDTBT:PCBM, lowering both the intensity and lifetime. ${ }^{27,} 28$ It was proposed that the improved nanomorphology in blends with the additive allowed a greater delocalisation of the CT states at the polymer/fullerene interface, decreasing their binding energy and allowing them to dissociate more easily, thus enhancing the charge carrier photogeneration yield. Formation of this emissive CT state was therefore suggested to be a loss pathway. ${ }^{19,20,30,37}$

Studies on Si-PCPDTBT, the silole analogue of PCPDTBT, revealed that no $\mathrm{CT}$ emission was observed in this polymer's blends with PCBM. ${ }^{30,38}$ Furthermore, this system outperforms PCPDTBT in terms of device characteristics, without the requirement for a processing additive. Indeed, the use of an additive with Si-PCPDTBT produces no discernible benefits. This was attributed to its enhanced crystallinity compared to PCPDTBT, leading to a higher charge carrier mobility, and thus the additive is unable to produce further improvements to the crystallinity. ${ }^{38}$

In this paper we focus on a comparison of two polymers that, like PCPDTBT and Si-PCPDTBT, vary by only one atom in their molecular structure. Indeed, PDTSiTTz has the same donor unit as Si-PCPDTBT and its carbon analogue PCPDTTTz has the same donor unit as PCPDTBT. The structures of PCPDTTTz (poly[2,6-(4,4-bis-(2-ethylhexyl)-4Hcyclopenta[2,1-b;3,4-b’]-dithiophene)-alt-(2,5-bis 3tetradecylthiophen-2-yl thiazolo 5,4-d thiazole)-2,5diyl]) and PDTSiTTz (poly[(4,4'- bis (2-ethylhexyl) dithieno [3,2-b:2',3'd] silole) -2,6-diyl-alt-(2,5-bis 3-tetradecylthiophen-2-yl thiazolo 5,4-d thiazole)-2,5diyl], also known as $\mathrm{KP} 115^{8,39,40}$ ) are shown in Figure 1a.

The effect of the processing additive 1,8-diiodooctane (DIO) on device performance is investigated for PCPDTTTz and PDTSiTTz blended with PCBM. The motivation behind this study is to investigate if the same charge transfer state behaviour is observed with $\mathrm{Si}$ atom substitution and/or use of processing additives, as compared to the previously studied PCPDTBT/Si-PCPDTBT. The purpose of this comparison is two-fold: firstly, to verify if emissive CT state formation is a loss pathway, as is the case for PCPDTBT:PCBM. ${ }^{19,} 20,30,37$ Secondly, the polymer PDTSiTTz has an unusual but highly desirable characteristic: it displays non-Langevin (supressed) bimolecular recombination, leading to long-lived charge carriers. $^{8}$ Its charge transfer characteristics are therefore of particular relevance. ${ }^{41}$ The additive DIO was chosen because it provided a larger beneficial effect for PCPDTTTz:PCBM compared to other additives such as ODT.

It was discovered that while the DIO causes a large improvement in device efficiency for PCPDTTTz:PCBM, there are negligible (even detrimental) changes for PDTSiTTz:PCBM instead. Steady state and time-resolved photoluminescence measurements reveal an emissive charge transfer state for PCPDTTTz:PCBM. This CT state can be quenched when the DIO is added, and this is correlated with a higher charge carrier density. Conversely, an extremely weak CT emission is observed for PDTSiTTz:PCBM, which is not quenched by DIO. This may be because the CT state itself is less emissive in this higher crystallinity system, or could be because the CT state can dissociate more rapidly into charge carriers, leading to higher overall charge photogeneration yields and device efficiencies, as observed experimentally.

This is only the second time that quenching of a polymer:fullerene CT state with a processing additive has been reported. Indeed, the similarities in the CT state behaviour of PCPDTTTz:PCBM and PCPDTBT:PCBM are very surprising considering the differences in the two polymers with respect to molecular structure and weight, structural order, bimolecular recombination kinetics, and band gap. This is an important result, particularly considering that PCPDTTTz:PCBM shows substantially smaller morphological changes compared to PCPDTBT:PCBM. This observation, in addition to the ability of the Si bridging atom to once again significantly alter the CT state behaviour compared to its carbon-based analogue, provide further insight into the role of CT states as a potential loss mechanism in organic photovoltaics.

\section{Results and Discussion}

\section{JV curves}

The $J V$ curves of PCPDTTTz:PCBM and PDTSiTTz:PCBM devices, showing the effect of the additive DIO, are displayed in Figures $1 \mathrm{~b}$ and $1 \mathrm{c}$ and summarised in Table 1. The overall effect of the diiodooctane additive for PCPDTTTz:PCBM 
photovoltaic devices is to improve the efficiency. This occurs as a result of a substantial increase in both short circuit current $J_{S C}$ and fill factor, FF, with $J_{S C}$ increasing from 3.6 to $7.1 \mathrm{~mA}$ $\mathrm{cm}^{-2}$ and the FF improving from 0.38 to 0.58 in the example shown. Furthermore, the additive removes the reproducible Sshape kink in the $J V$ curve. The cause of this double-diode kink is unknown, but is typically attributed to charge blocking, induced interfacial dipoles, ${ }^{42}$ space charges created by reduced surface recombination, ${ }^{43}$ and other detrimental effects. A drop in open circuit voltage $V_{O C}$ is present when the additive is used: such a decrease has been seen for other systems ${ }^{31,44}$ and has previously been attributed to ordering of the active layer induced by the $\mathrm{DIO}^{45}$ and lowering of the energy of the charge transfer state. ${ }^{34}$

Table 1. $J V$ parameters of PCPDTTTz:PCBM and PDTSiTTz:PCBM devices, with and without DIO, correlated with the extracted charge density measured at $200 \mathrm{~ns}$.

\begin{tabular}{|c|c|c|c|c|c|}
\hline System & $\begin{array}{c}n(\times \\
10^{16} \\
\left.\mathrm{~cm}^{-3}\right)\end{array}$ & $\begin{array}{c}J_{S C} \\
(\mathrm{~mA} \\
\left.\mathrm{cm}^{-2}\right)\end{array}$ & $\begin{array}{c}V_{O C} \\
(\mathrm{~V})\end{array}$ & $F F$ & $\begin{array}{c}\text { Efficiency } \\
(\%)\end{array}$ \\
\hline PCPDTTTz:PCBM & 2.3 & 3.6 & 0.69 & 0.38 & 0.95 \\
\hline $\begin{array}{c}\text { PCPDTTTz:PCBM } \\
\text { / DIO }\end{array}$ & 3.7 & 7.1 & 0.60 & 0.58 & 2.5 \\
\hline PDTSiTTz:PCBM & 4.9 & 9.5 & 0.60 & 0.64 & 3.6 \\
\hline $\begin{array}{c}\text { PDTSiTTz:PCBM } \\
\text { / DIO }\end{array}$ & 4.1 & 8.5 & 0.57 & 0.55 & 2.7 \\
\hline
\end{tabular}

Despite the decrease in $V_{O C}$ for PCPDTTTz:PCBM, the significant increases in $J_{S C}$ and FF compensate for this such that the overall impact is an increase in power conversion efficiency from only $0.95 \%$ to $2.5 \%$. These are similar trends to those reported for PCPDTBT:PCBM. ${ }^{31}$ This increase in efficiency has typically been attributed to an enhancement in the solvation of the PCBM, leading to an improved morphology and phase separation ${ }^{44}$ with a consequently higher charge photogeneration yield, due to an enhancement in the dissociation of the charge transfer state. ${ }^{24,25,35}$

The PDTSiTTz:PCBM photovoltaic devices (Figure 1b), however, do not show this trend. The DIO additive does not improve the efficiency; indeed, the efficiency is slightly lower in this particular example. All of the parameters show small decreases such that the overall efficiency decreases from 3.6\% to $2.7 \%$. However, results taken over a large number of devices (Supporting Information, Figure S1) show that the DIO has a negligible effect for thin active layer PDTSiTTz:PCBM devices and a small decrease in performance for thicker devices, as in the above example. It is worth noting that the efficiency of the PDTSiTTz device without additive is higher than the efficiency of the PCPDTTTz device with additive. ${ }^{30,38}$
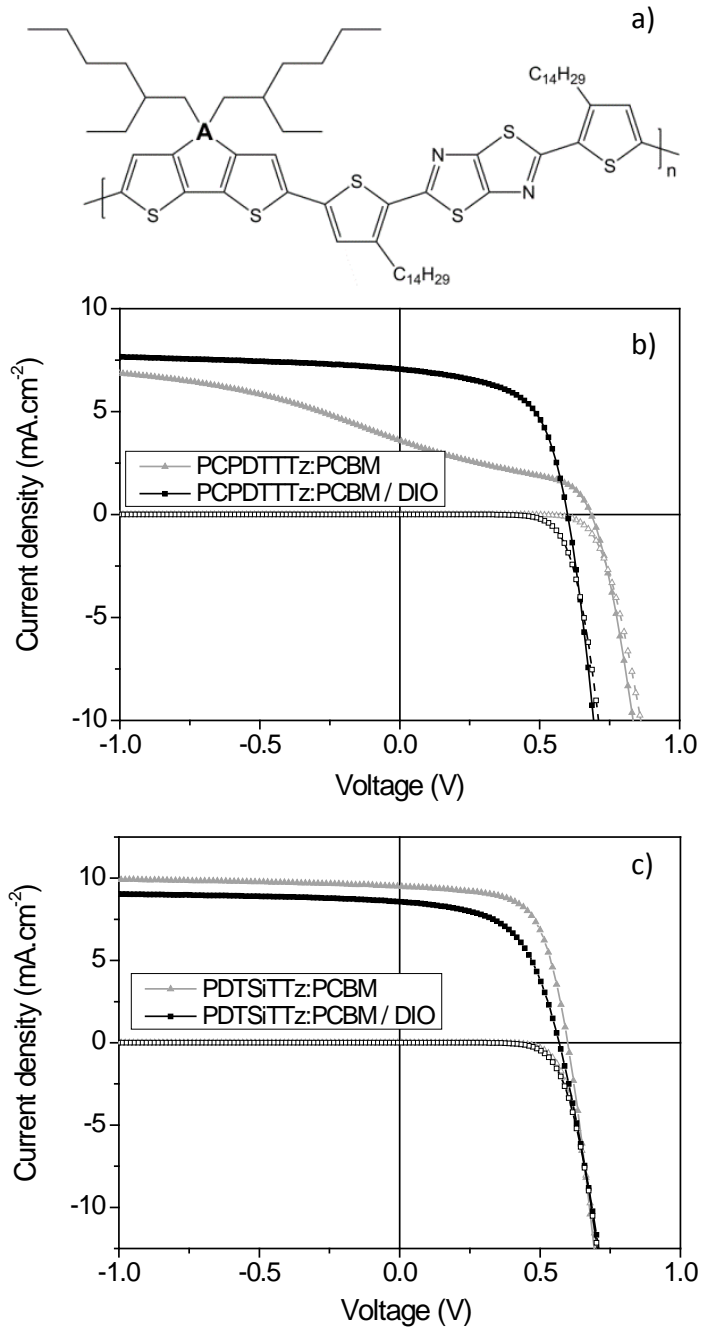

Figure 1. The generalised structure of the polymers studied here, where $A=S i$ is PDTSiTTz and $\mathrm{A}=\mathrm{C}$ is PCPDTTTz (a). JV curves of the encapsulated PCPDTTTz:PCBM (b) and PDTSiTTz:PCBM (c) devices, with and without DIO. All are $1: 2$ by weight.

\section{Morphology}

Two-dimensional GIWAXS (grazing incidence wide-angle Xray scattering) patterns are shown in Figure 2. For the as-cast PCPDTTTz:PCBM blend films without DIO (Figure 2a), there is a scattering peak observed at $\mathrm{q} \sim 0.30 \AA^{-1}$ that is much more intense along the $\mathrm{q}_{\mathrm{r}}$ axis. This corresponds to the lamellar stacking of PCPDTTTz semi-crystalline domains normal to the surface substrate, with a layer spacing of $25 \AA$. The $\pi-\pi$ stacking peak is most intense along the $\mathrm{q}_{\mathrm{z}}$ axis and its position at $\mathrm{q} \sim 1.7 \AA^{-1}$ corresponds to a $\pi-\pi$ stacking distance of $3.7 \AA$, a distance typical for conjugated polymers such as $\mathrm{P}_{3} \mathrm{HT}^{46}{ }^{4}$ In addition, the broad ring of scattering at $1.4 \AA^{-1}$ corresponds to phase-separated, non-crystalline PCBM. The broad scattering 
profiles suggest a low degree of crystallinity for the polymer domain. For PCPDTTTz:PCBM blend films prepared with DIO, (Figure 2b), the lamellar scattering ring is of uniform azimuthal intensity indicating a random orientation of domains. In addition, the rings of scattering are broader which indicates shorter-range positional correlations.

Interestingly, there exists an additional scattering peak located at q 1.05 $\AA^{-1}$ for the two PCPDTTTz:PCBM films. These peaks are reasonably sharp and correspond to a length scale of $\sim 6 \AA$. In the absence of DIO, these peaks are weaker and more powder-like. After the addition of DIO, these peaks become stronger and concentrated at polar angles (relative to the $\mathrm{q}_{\mathrm{r}}$ axis) of 90,60 , and $0^{\circ}$. This unusual and apparently regular angular distribution reflects the most prominent structural change that occurs with the introduction of DIO, although its exact origin cannot be explained on the basis of the present results. These sharp peaks are unlikely to originate from either a pure PCBM or PCPDTTTz phase, since these exhibit much broader diffraction features. It is possible that these peaks originate from a blend phase that incorporates both PCPDTTTz and PCBM, the presence of which is promoted by the DIO. Furthermore, the peak cannot be indexed from these pure phases. $^{47}$ It is also important to note that these structural changes are considerably smaller than those observed for PCPDTBT:PCBM when an additive is used. ${ }^{30,32}$
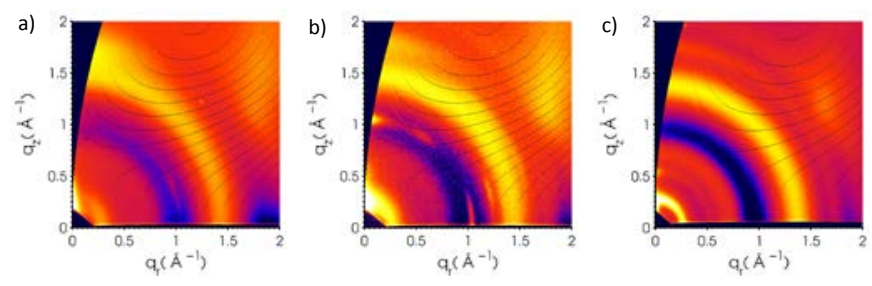

Figure 2. Two-dimensional GIWAXS images for (a) PCPDTTTz:PCBM (b) PCPDTTTZ:PCBM with DIO and (c) PDTSiTTz:PCBM films. Note that the black curves in each image are missing pixels introduced when converting CCD measured images to q-space images.

For the PDTSiTTz:PCBM films the lamellar peak and $\pi-\pi$ peak are observed at $\mathrm{q} \sim 0.30$ and $1.7 \AA^{-1}$, respectively, the same positions as observed for the PCPDTTTz:PCBM films. However, the molecular order and crystallinity are better than both PCPDTTTz:PCBM films, as indicated by the stronger intensity and narrower radial widths of the peaks. Furthermore, a similar angular distribution is observed for PDTSiTTz:PCBM without DIO compared to that measured in PCPDTTTz:PCBM with DIO.

\section{Steady state absorption and photoluminescence}

The absorption spectra of PDTSiTTz and PCPDTTTz blends with PCBM, showing the influence of the processing additive DIO, are displayed in Figure 3. The spectrum of PDTSiTTz:PCBM shows no shifts in wavelength or relative intensity in the polymer absorption bands (590 and $640 \mathrm{~nm}$ ) when fabricated with DIO. PCPDTTTz:PCBM has a very similar absorption spectrum compared to PDTSiTTz:PCBM, owing to their structural similarities, with polymer bands at 585 and $630 \mathrm{~nm}$. However, there is a small, reproducible red-shift of $3-7 \mathrm{~nm}$ for both polymer peaks when the DIO is employed. This shift is significantly smaller compared to PCPDTBT:PCBM, where the polymer absorption band redshifts by $60 \mathrm{~nm}$ with ODT. ${ }^{33}$ This implies that the increases in crystallinity and packing order in PCPDTTTz:PCBM with additive are substantially smaller than for PCPDTBT:PCBM (and may be virtually non-existent for PDTSiTTz), as observed in the GIWAXS data.
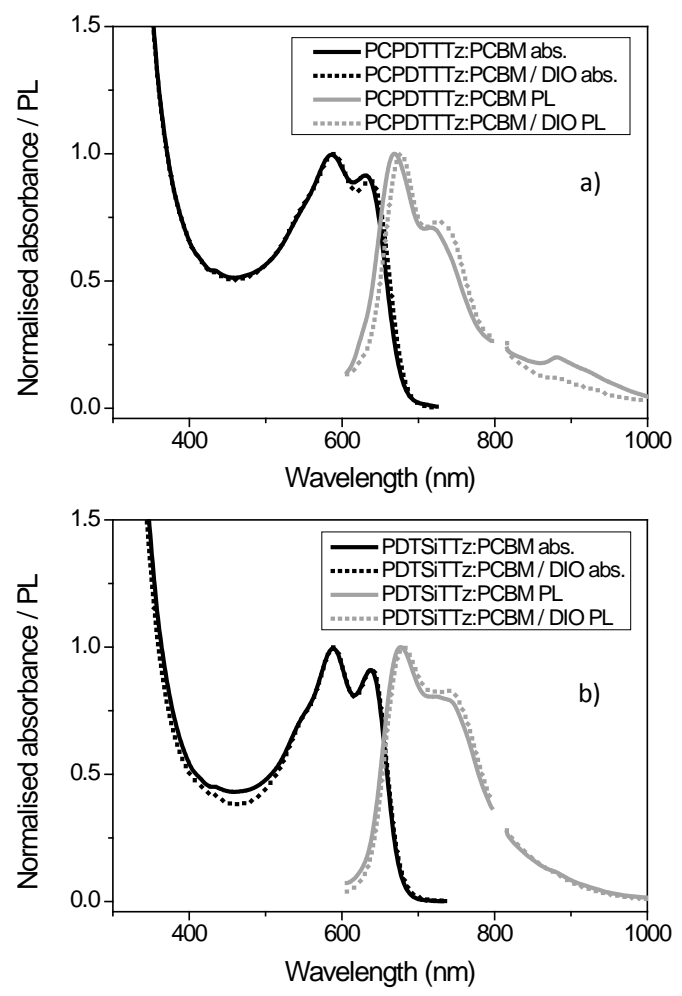

Figure 3. The steady state normalised absorbance (abs.) and photoluminescence (PL) for the PCPDTTTz:PCBM (a) and PDTSiTTz:PCBM (b) blends, showing the effect of the DIO. The gap at $800 \mathrm{~nm}$ in the PL spectra is due to the excitation wavelength harmonic.

The steady-state photoluminescence (PL) spectra of the PCPDTTTz:PCBM and PDTSiTTz:PCBM blends are also shown in Figure 3. The PCPDTTTz:PCBM PL spectrum shows that the $670 \mathrm{~nm}$ PL band and longer wavelength shoulder at 715 $\mathrm{nm}$ (both assigned to the polymer $\mathrm{S}_{1}$ state) are joined by an additional weak but broad PL band centred at $885 \mathrm{~nm}$ and 
extending beyond $1000 \mathrm{~nm}$. This additional band, which is not present in the pristine polymer emission spectrum nor in that of pristine PCBM, is thus assigned to the PCPDTTTz:PCBM CT state, owing to its similar spectral behaviour compared to other polymer/fullerene systems. ${ }^{27,}{ }^{28}$ It is worth noting that this CT emission is substantially weaker than the polymer emission bands - unlike PCPDTBT:PCBM, where the CT state emission is relatively strong. This could be because of a lower emission quantum yield for the PCPDTTTz:PCBM CT state, a lower concentration of CT states, or both. Despite the weak intensity of this CT emission band, the DIO is able to quench a significant proportion of the band, such that any remaining intensity overlaps with the residual polymer emission tail. The PDTSiTTz:PCBM PL spectrum has a primary PL peak at 680 $\mathrm{nm}$ with a prominent shoulder at longer wavelengths. No evidence of a red-shifted CT state emission peak is observed here, although any weak CT emission is likely to overlap with the tail of the polymer emission. Addition of DIO to the blend makes no significant difference to the PL spectrum.

\section{Charge photogeneration: charge extraction and TAS}

Charge extraction measurements were performed on the above devices in order to assess the charge photogeneration yields. This technique utilises a solar relay switch, ${ }^{8,} 39$ where charges are photogenerated in a photovoltaic device held at open circuit. Switching to short circuit after an adjustable delay time allows charge extraction to occur under the influence of the built-in field. The results measured at 200 ns (Table 1) show that the two PDTSiTTz:PCBM devices have the highest charge carrier densities, with a drop in charge density, $n$, when the additive is employed. PCPDTTTz:PCBM shows the opposite trend, where addition of DIO increases the charge carrier density by a factor of $60 \%$. These results are entirely consistent with the measured short circuit currents: the PDTSiTTz devices have higher $J_{S C}$ and charge density values compared to PCPDTTTz, and the changes in charge density with addition of DIO mirror the changes in $J_{S C}$ in these particular devices.

Transient absorption spectroscopy (TAS) is a very useful technique as it directly monitors the optical absorption of photogenerated transient species, offering insight into the identity, yield and dynamics of these transient species. For polymer:PCBM blends on the nanosecond-millisecond timescales (as utilised here), these are typically charge carriers - polymer polarons and fullerene anions - or, in less efficient blends, triplet states. This method is widely known and has previously been applied to numerous polymer:blend systems. ${ }^{12}$, $25,33,48-54$ Interestingly, it has been reported that the $\triangle O D$ (which is directly proportional to the charge carrier density) of the polymer polaron transient absorption band at $1 \mu \mathrm{s}$ of a polymer:PCBM blend film is directly correlated with the $J_{S C}$ of the resultant photovoltaic device. ${ }^{55}$ Previously it has also been observed with PCPDTBT:PCBM that use of the additive ODT causes a large increase in charge photogeneration yield, as suggested by the increase in the $\triangle O D$ of the polymer polaron transient absorption peak at $1280 \mathrm{~nm} .{ }^{33}$ This forms a large contribution to its increase in $J_{S C}$ and overall device performance when the additive is employed.

Transient absorption spectroscopy was performed on PCPDTTTz:PCBM blend films with and without the DIO (Figure 4). PCPDTTTz:PCBM shows a substantial increase in signal amplitude, $\triangle O D$, upon addition of DIO. This is evident in both the spectrum and the charge carrier decay dynamics. The transient absorption spectrum of PCPDTTTz:PCBM has a broad, weak band at approximately $1100 \mathrm{~nm}$ (Supporting Information, Figure S3), which becomes better resolved when the sample incorporating DIO is measured (Figure 4a). The spectrum of PCPDTTTz:PCBM with DIO shows a clear, strong band centred at $1050 \mathrm{~nm}$, with a tail of a second band evident below $750 \mathrm{~nm}$. This spectrum is very similar to that of structurally analogous PDTSiTTz:PCBM previously published $^{56}$ and compared in Figure 4a. The $1050 \mathrm{~nm}$ peak can therefore be assigned to localised PCPDTTTz polymer polarons, while the tail below $750 \mathrm{~nm}$ can be assigned to delocalised PCPDTTTz polymer polarons. The substantial increase by a factor of almost four in the signal amplitude $\triangle O D$ of the PCPDTTTz localised polaron band when the DIO is used, as also evident from the dynamics presented in Figure 4b, indicates a large increase in charge photogeneration yield. This is consistent with both the charge extraction and $J_{S C}$ results. 


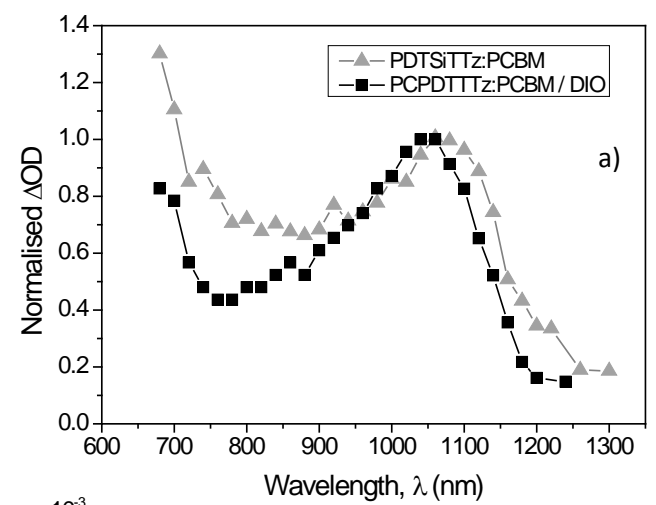

that the $\triangle O D$ and thus charge photogeneration yield of PDTSiTTz:PCBM is significantly higher than that of PCPDTTTz:PCBM, even with the DIO. This observation is consistent with the $J_{S C}$ and charge extraction results.

\section{Time-resolved photoluminescence}

The charge transfer state observed for PCPDTTTz:PCBM was investigated further using time-resolved photoluminescence. This presented a number of challenges owing to the properties of PCPDTTTz, PDTSiTTz, and their blends with PCBM. Firstly, the emission of the pristine polymers has a substantially weaker quantum yield than either PCPDTBT or Si-PCPDTBT. All experiments were therefore done on encapsulated quartz samples to avoid any spurious signals. Furthermore, the emission extends over the $600-950 \mathrm{~nm}$ region, with the CT emission expected between 850 and $1050 \mathrm{~nm}$, and thus both visible and infrared detection were required.

The visible streak camera results for pristine PDTSiTTz and PCPDTTTz films (without PCBM) on encapsulated quartz are shown in the left column of Figure 5. The corresponding photoluminescence decays are displayed in Figure S3, and compared to that of PCPDTBT and Si-PCPDTBT films. Pristine PDTSiTTz and PCPDTTTz show a similar trend to the other polymer pair, with the silicon analogues PDTSiTTz and Si-PCPDTBT having a very similar monoexponential lifetime of $\sim 290$ ps while the carbon analogues PCPDTTTz and PCPDTBT have a shorter lifetime (130 ps for PCPDTTTz).

Furthermore, it is evident from Figure 4b that the charge carrier dynamics of the PCPDTTTz:PCBM blend film, using a probe wavelength of $1000 \mathrm{~nm}$, do not alter significantly upon addition of DIO. Both decays follow a power law, $\triangle O D \propto t^{-\alpha}$, which is consistent with models depicting bimolecular recombination of dissociated charge carriers in the presence of an exponential distribution of localised states. ${ }^{57-60}$ This power law decay behaviour has been observed in P3HT, polyselenophenes, and MDMO-PPV, all blended with various fullerene derivatives. Typically an increase in crystallinity increases the gradient of the power law, $\alpha$, (denoting fewer deep trap states) as was observed when both increasing the regioregularity of P3HT:PCBM ${ }^{61}$ and during its thermal annealing. ${ }^{57}$ However, this is not the case for PCPDTTTz:PCBM, for which the relatively fast decay of $\alpha=0.61$ does not change with DIO. This lack of change in $\alpha$ is consistent with the GIWAXS data on the PCPDTTTz:PCBM system, which show only small increases in packing order when the additive is employed.

The transient absorption spectroscopy of PDTSiTTz:PCBM (1:2) blend films has been covered extensively in a previous publication, $^{56}$ so in this paper only the comparison with PCPDTTTz:PCBM is highlighted. It is clear from Figure $4 \mathrm{~b}$

The polymer:fullerene blends were firstly examined using a PCBM concentration of $25 \%$ by weight (Figures 5 and 6). This quantity was chosen in order to induce substantial exciton quenching with a blend nanomorphology, but still retain enough PL quantum yield to achieve a reasonable signal-tonoise ratio. The addition of 25\% PCBM to these polymers reduces the polymer $\mathrm{S}_{1}$ photoluminescence lifetime considerably, as expected for polymer exciton quenching. This is shown in Figure 6a for PCPDTTTz and in Figure 6b for PDTSiTTz (and the middle and right columns of Figure 5) using infrared detection; hence only the tail of the pristine polymer emission is measured. This was done in order to more accurately observe the CT state. Upon addition of PCBM, the lifetime measured at the polymer's $S_{1}$ band in the $800-830 \mathrm{~nm}$ range decreases to $\sim 15$ ps for both PCPDTTTz:PCBM and PDTSiTTz:PCBM, close to the instrument response. The polymer emission is not completely quenched by the PCBM at this relatively low concentration, hence the lifetime still has a long-lived component. Also apparent in the PL plots (top-right of Figure 5b, Figure 6a) is a clear CT state emission for PCPDTTTz:PCBM, with a red-shifted, long-lived, broad emission from $\sim 900-1150 \mathrm{~nm}$. The CT state PL decay in Figure 6a can be fitted by two lifetimes: 20 ps (residual 
polymer $\mathrm{S}_{1}$ emission) and $\sim 750$ ps (the CT state emission). Due to the overlap between the polymer $S_{1}$ and CT state PL peaks, it is difficult to acquire an exact lifetime of the CT state emission.

The CT state of PCPDTTTz:PCBM was examined further by assessing the dependence on PCBM concentration. The results are displayed in Figure S4, noting that the very efficient exciton quenching at high PCBM loadings leads to an extremely weak emission signal. The photoluminescence lifetime of the CT state clearly decreases as the concentration of PCBM increases, achieving 360 ps with 67\% PCBM. This is due to the CT state being more easily dissociated when large domains of PCBM are present: the increase in the blend's overall dielectric constant reduces the coulomb attraction between the two charges at the interface, allowing more efficient dissociation into free charge carriers. ${ }^{9,26,62}$
Unexpectedly, the CT state was also observed for PDTSiTTz (Figure 5 and 6b) at low PCBM concentrations of 25\%, despite not being seen for its analogue Si-PCPDTBT. The PDTSiTTz:PCBM CT state is, however, extremely weak, with a lifetime of $\sim 400$ ps: almost half that of PCPDTTTz:PCBM's at the same PCBM concentration. Although this could simply be that the PDTSiTTz:PCBM CT state has a lower quantum yield of emission than that of PCPDTTTz:PCBM, the higher charge photogeneration yields observed for PDTSiTTz:PCBM indicate that its CT state is able to dissociate into free charge carriers more easily. The PDTSiTTz:PCBM CT state is also almost completely absent at high PCBM loadings, suggesting that the dielectric constant effect ${ }^{62}$ is additional to the CT state's ability to dissociate efficiently or that, in fact, a CT state does not form at all under high PCBM loadings.
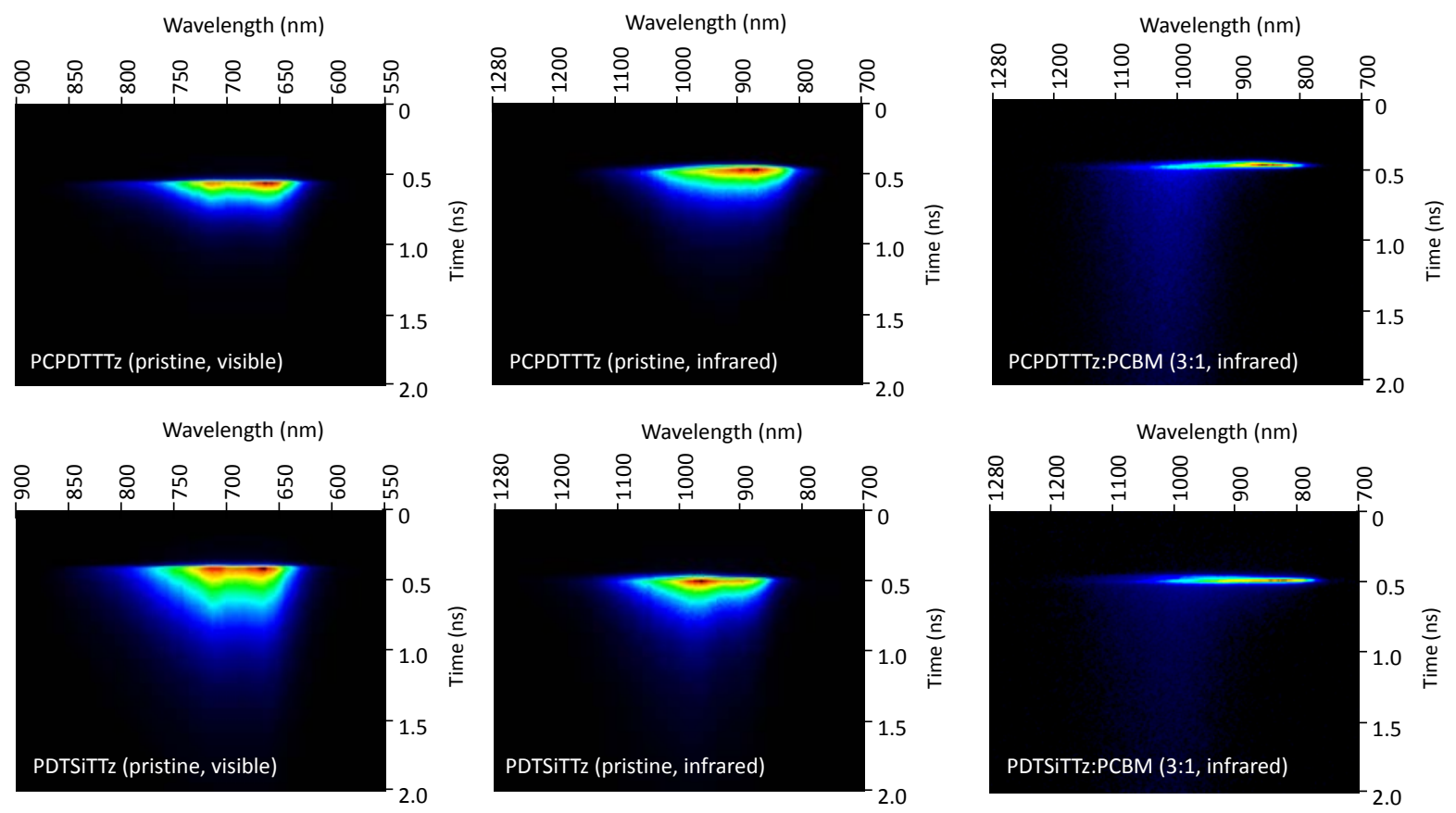

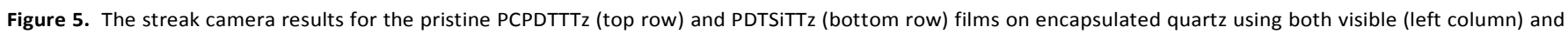
infrared (middle column) detection, compared to the corresponding 3:1 blend films with PCBM (right column). 


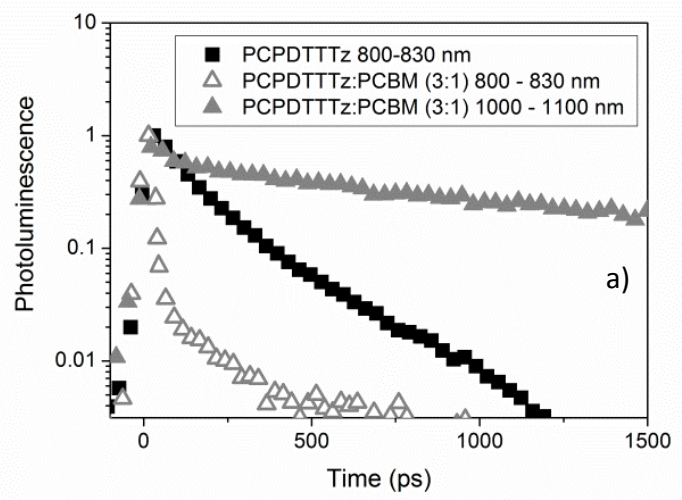

observed CT photoluminescence, low charge photogeneration yields, and poor device performance.

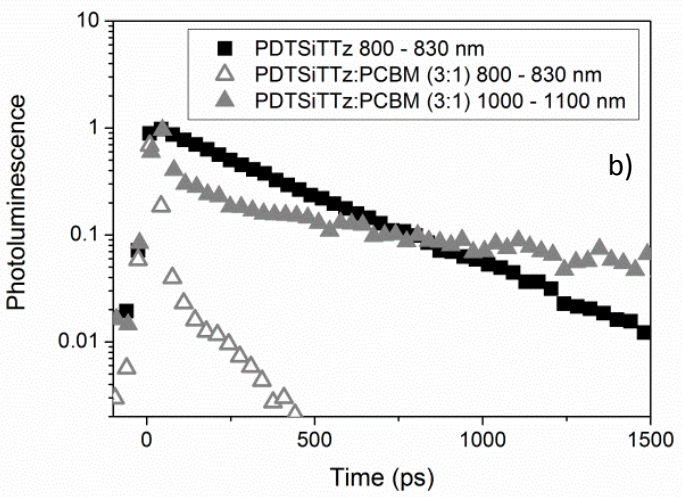

Figure 6. The photoluminescence decays with time for pristine PCPDTTTz (a) and PDTSiTTz (b) and their 3:1 blends with PCBM, on encapsulated quartz and measured in the spectral ranges $800-830 \mathrm{~nm}$ (polymer emission) and 1000$1100 \mathrm{~nm}$ (CT state emission).

Finally, the effect of DIO was investigated (Figure 7). In the case of PCPDTTTz:PCBM with low PCBM concentrations (5 $25 \%$ ), the CT state emission's lifetime and intensity decreased when the DIO was used. Complete CT state quenching only occurred at the highest PCBM concentration of $67 \%$, with a reduction of the $\mathrm{CT}$ state lifetime to only 50 ps (although a small long-lived component still exists). In the case of PDTSiTTz:PCBM (1:2), the DIO has little quenching effect. A probable reason for this is a very low concentration of emissive CT states present in an already well phase-segregated blend.

The results presented above indicate that for PCPDTTTz:PCBM, like PCPDTBT:PCBM, the emissive CT state appears to be a loss mechanism. ${ }^{27,28}$ After the polymer $S_{1}$ state forms upon absorption of light, exciton dissociation at the polymer/fullerene interface leads to a CT state. Whether this CT state is simply one of many within a manifold of CT states, a vibrationally excited 'hot' CT state, or a relaxed CT state is unclear from the presented data. Regardless, this CT state can undergo full dissociation to create free charge carriers or recombine radiatively. In the case of PCPDTTTz:PCBM, it seems this latter process has a higher rate, thus leading to the

The conclusion that formation of an emissive CT state in PCPDTTTz:PCBM is primarily a loss pathway is particularly apparent from the addition of DIO to PCPDTTTz:PCBM, which reduces the CT state emission intensity and lifetime, increases the charge photogeneration yield and ultimately improves the device performance. This is most likely due to an enhancement in the rate of CT state dissociation, thereby reducing the percentage of excitons that follow the CT state emission pathway. Interestingly, this alteration in CT state behaviour for PCPDTTTz:PCBM when the additive is employed does not seem to be accompanied by a substantial change in structural order. This is very different behaviour to that observed for PCPDTBT:PCBM, for which significant morphological changes were measured with an additive.

For PDTSiTTz:PCBM, the high charge photogeneration yields and very weak, short-lived CT state emission suggest that very few excitons follow the CT state emission pathway, unlike PCPDTTTz:PCBM. Instead, it appears that the CT state dissociation pathway is very efficient in this system. This is supported by the lack of effect of the DIO on the CT state, charge photogeneration and device performance, thereby 
indicating that CT state dissociation into free charge carriers is already a relatively efficient process.

The observation of CT state emission as a loss pathway in systems such as PCPDTBT:PCBM and PCPDTTTz:PCBM does not conflict with results from groups such as Neher et al, ${ }^{15}$ who suggest that it may also be possible to generate free charge carriers from a low-energy CT state. ${ }^{16,17,28}$ Our results indicate that it is the kinetic branching ratio between CT state dissociation and radiative recombination that directly influences the charge photogeneration yield (and, ultimately, the internal quantum efficiency) for PCPDTTTz:PCBM and PDTSiTTz:PCBM. As such, a short emissive CT state lifetime appears to be correlated with a higher charge photogeneration yield. This conclusion is likely to be extendable to other systems where an emissive CT state is possible, which are known to exhibit a variety of charge photogeneration yields and internal quantum efficiencies: ${ }^{15}$ possibly a result of differing kinetic branching ratios. The pertinent question, therefore, is what the lifetime of each CT state is, and thus the fraction that can dissociate into free charge carriers. An emissive CT state with a high rate of recombination back to the ground state will have a low charge photogeneration yield (and thus a low internal quantum efficiency), as observed for PCPDTTTz:PCBM. Note that non-emissive CT states are also possible, and a similar kinetic branching ratio invoking nonradiative geminate recombination would still apply.

PDTSiTTz and PCPDTTTz have very similar HOMO and LUMO energy levels, thus should have a similar CT state energy. It is therefore unlikely to be a difference in driving force of charge separation that is the cause of their different CT state dissociation behaviour. A difference in charge carrier mobility may play a role in the ability of the CT state to fully dissociate, as charge carriers with higher mobility are more likely to be able to escape the coulomb capture radius. PDTSiTTz:PCBM has indeed been reported to have a relatively high mobility, ${ }^{56}$ although the pertinent mobility would have to be measured on the femtosecond-picosecond timescales. As suggested by several authors, ${ }^{13}, 14,28,63$ the ease with which PDTSiTTz:PCBM's CT state can dissociate into free charge carriers may be related to a more spatially delocalised CT state, lowering its binding energy.

The similarities in the CT state behaviour of PCPDTTTz:PCBM compared to PCPDTBT:PCBM are quite remarkable considering the differences in molecular structure and weight, solubility, degree of order, crystal structure, bimolecular recombination kinetics, and band gap between the two. The quenching of a CT state through use of a processing additive is by no means a general phenomenon. However, the fact that it has been observed in this PCPDTTTz:PCBM system is an important result, particularly since the morphological changes observed are significantly smaller. The role of this bridging atom in excited state dynamics needs to be further investigated, particularly the modifications that occur when it is replaced by an Si atom.

The observation of an emissive - but easily dissociable - CT state for PDTSiTTz:PCBM, while none at all was observed for Si-PCPDTBT:PCBM, is also an important finding. Interestingly, PDTSiTTz:PCBM is known to be one of the few reported non-Langevin polymer/fullerene systems in the literature: it has bimolecular recombination that is reduced compared to that expected for diffusion-limited Langevin recombination, leading to long-lived charge carriers. ${ }^{8}$ One theory is that a species approximating the CT state must reform during bimolecular recombination; ${ }^{41}$ if this species can easily dissociate again, then relatively few charge carriers will follow the full recombination pathway back to the ground state - and the charge carrier lifetime would be much longer. This theory is consistent with the presented data indicating a relatively rapid dissociation of the CT state for PDTSiTTz:PCBM.

\section{Conclusions}

The device performance of two structurally analogous polymers PCPDTTTz and PDTSiTTz blended with PCBM was investigated, in particular with regards to the effect of the processing additive DIO. It was observed that the DIO had a significant beneficial effect for PCPDTTTz:PCBM photovoltaic devices, but negligible or even detrimental effects for PDTSiTTz:PCBM devices.

GIWAXS results show that the substantial structural changes previously observed for PCPDTBT:PCBM with incorporation of an additive are not present for PCPDTTTz:PCBM. However, a well-ordered angular distribution was observed as an additional scattering peak, which may be due to some form of blend phase that increases in prominence when the DIO is used. Results for PDTSiTTz:PCBM show a substantially higher degree of crystallinity.

Time-resolved charge extraction experiments and transient absorption spectroscopy results show that for PCPDTTTz:PCBM the addition of DIO improves the charge carrier photogeneration yield significantly. Steady state and time-resolved photoluminescence measurements revealed an emissive charge transfer state for PCPDTTTz:PCBM. This emission is mostly quenched when the DIO is employed, as was observed for PCPDTBT:PCBM. Indeed, this is only the second time that the presence of an emissive CT state that can be quenched by addition of DIO - and is correlated with an improved photovoltaic device performance - has been reported. In this case it appears that formation of an emissive CT state is a loss mechanism. The increase in device performance upon 
addition of DIO for PCPDTTTz:PCBM can therefore be assigned to a reduction in the emission of the CT state, which improves the charge photogeneration yield.

Conversely, only an extremely weak CT emission was observed for PDTSiTTz:PCBM, which was not quenched by DIO. This lack of strong emission may be because the CT state in this higher crystallinity system can dissociate more efficiently into charge carriers, leading to a higher charge photogeneration yield and superior device performance.

\section{Experimental}

Device fabrication. Devices of PCPDTTz:PC ${ }_{61} \mathrm{BM}$ and PDTSiTTz:PC ${ }_{61} \mathrm{BM}$ (1:2 by weight) were fabricated using the same method as Peet et al. ${ }^{40}$ with an inverted Ag/hole-injecting layer (HIL)/active layer/ electron-injecting layer (EIL)/ITO structure, where the HIL and EIL are Konarka proprietary materials. The $\mathrm{PC}_{61} \mathrm{BM}(99.5 \%$ purity) was sourced from Solenne and the two polymers were provided by Konarka Technologies Limited, synthesised using the procedure in reference 40 . No thermal annealing was performed. For those devices with 1,8-diiodooctane (Aldrich, 98\% purity), a $2 \%$ by volume quantity was added to the o-dichlorobenzene (Aldrich, anhydrous, 99\% purity) solution prior to stirring overnight at $120^{\circ} \mathrm{C}$. The active layer thickness was $150 \mathrm{~nm}$ with an active area of $\sim 17 \mathrm{~mm}^{2}$, which was doctor blade-coated using solutions at $70^{\circ} \mathrm{C}$. Devices with DIO were dried in a low vacuum for 1 hour prior to coating layers on top of the active layer. Devices were fabricated in air, then transferred to a glovebox for epoxy encapsulation with a glass cover layer. Device efficiencies were measured with a Newport-Oriel AAA certified solar simulator operating at $100 \mathrm{~mW} \mathrm{~cm}^{-2}$. Solar simulator illumination intensity was calibrated using a standard silicon photovoltaic with a protective KG5 filter calibrated at the National Renewable Energy Laboratory.

GIWAXS. The GIWAXS experiments were performed at the X9 undulator beamline at the National Synchrotron Light Source, Brookhaven National Laboratory, where the $14.0 \mathrm{keV}$ photons $(\lambda=0.0886 \mathrm{~nm})$ are focused to a spot with a height of $80 \mu \mathrm{m}$ and a width of $200 \mu \mathrm{m}$, at the sample position. The Xray incident angle was set to $\sim 0.15^{\circ}$, an angle above the critical angle of the polymer so as to assure a full penetration into the film. The diffraction images reveal the sample's out-of-plane structure (normal to the substrate) along the vertical axis $\left(\mathrm{q}_{\mathrm{z}}\right)$ and in-plane structure (parallel to the substrate) along the horizontal axis $\left(\mathrm{q}_{\mathrm{r}}\right)$. The scattering/sample chamber vacuum was maintained at $\sim 10^{-2}$ torr at all temperatures to reduce thermal sample degradation, beam damage, diffuse scattering and X-ray absorption.
Microsecond-millisecond transient absorption spectroscopy. The encapsulated thin blend films (spin-coated) were excited in transmission mode by a laser pulse (6 ns, $532 \mathrm{~nm}$, repetition rate $10 \mathrm{~Hz}$ ) from a Nd:YAG laser (Spectra-Physics, INDI-4010) with a pump wavelength of $532 \mathrm{~nm}$, using a pump intensities of $3 \mu \mathrm{J} . \mathrm{cm}^{-2}$ and a repetition frequency of $10 \mathrm{~Hz}$. The Xe probe lamp (Edinburgh Instruments, Xe900) with a stabilised power supply, with a typical probe wavelength of $1000 \mathrm{~nm}$, adjustable using a monochromator. The probe light passing through the device was detected with a silicon (Femto, HCA-S-200M-SI) or an InGaAs photodiode (Femto, HCA-S200M-IN). The signal from the photodiode was amplified (Femto, DHPVA-200) and collected with a digital oscilloscope (Tektronics, DPO4054), which was synchronised with a trigger signal of the pump laser pulse from a photodiode (Newport, 818-BB-40).

Charge extraction. The device, held at open circuit, was illuminated by the laser pulse as described above. After 200 ns, extraction of the photogenerated charges under the built-in field was accomplished by switching to short circuit using a nanosecond time-resolved switch. The photocurrent was then integrated to ascertain the charge density at this delay time.

Time-resolved photoluminescence. Thin films were spincoated onto quartz substrates. Samples were excited by a $150 \mathrm{fs}$ pulsed Kerr mode locked Ti-sapphire laser at $760 \mathrm{~nm}$ or frequency doubled at $380 \mathrm{~nm}$. The steady state photoluminescence emission was measured with an Andor iDus InGaAs array detector. The spectra are corrected for the spectral response of the setup. Typical excitation power densities were $\sim 1 \mathrm{~mW}$ on a focused laser spot of about $100 \mu \mathrm{m}$ diameter. The time-resolved PL was recorded by two Hamamatsu streak cameras working in synchro-scan mode one near-infrared sensitive and the other visible sensitive. All the measurements were performed at room temperature. To avoid degradation, all samples were edge-sealed with a UV-curable epoxy in a $\mathrm{N}_{2}$-filled glovebox before the measurements.

\section{Acknowledgements}

TMC would like to thank the Australian Nanotechnology Network for an Overseas Travel Fellowship. This research was supported under the Australian Research Council's Linkage Projects funding scheme and by Konarka Technologies. AJM acknowledges the ARC for providing equipment support through LIEF, as well as supporting AJM and TMC with an Australian Research Fellowship and DECRA fellowship, respectively. Research at Brookhaven National Laboratory (X.L. and B.O) and the use of the National Synchrotron Light Source is supported by the Materials Sciences and Engineering Division of the U.S. Department of Energy (Contract No. DEAC02-98CH10886). MAL would like to thank the Foundation for Fundamental Research on Matter (FOM), which is part of 
the Netherlands Organization for Scientific Research (NWO), for granting the FOM Focus Group 'Next Generation Organic Photovoltaics', participating in the Dutch Institute for Fundamental Energy Research (DIFFER).

\section{Notes and references}

a. T. M. Clarke and A. J. Mozer

ARC Centre of Excellence for Electromaterials Science, Intelligent Polymer Research Institute, University of Wollongong, North Wollongong, NSW 2500, Australia

E-mail: tclarke@uow.edu.au

b. J. Peet, C. Lungenschmied, and N. Drolet.

Konarka Technologies, 116 John St., Suite 12, Lowell, Massachusetts 01852, USA.

c. X. Lu and B. Ocko

Condensed Matter Physics and Materials Science Department, Brookhaven National Laboratory, Upton, New York 11973, USA.

d. M. A. Loi

Zernike Institute for Advanced Materials, University of Groningen, Nijenborgh 4, 9747 AG Groningen, The Netherlands

Electronic Supplementary Information (ESI) available: summary of device data (Figure S1), transient absorption spectrum of PCPDTTTz:PCBM (Figure S2), PL decays of pristine polymers in solution and on film (Figure S3), and PL decays as a function of PCBM concentration (Figure S4). See DOI: 10.1039/b000000x/

1. Z. He, C. Zhong, S. Su, M. Xu, H. Wu and Y. Cao, Nat. Photonics, 2012, 6, 591.

2. X. Guo, N. Zhou, S. J. Lou, J. Smith, D. B. Tice, J. W. Hennek, R. P. Ortiz, J. T. L. Navarrete, S. Li and J. Strzalka, Nat. Photonics, 2013, 7, 825.

3. C. Deibel, V. Dyakonov and C. J. Brabec, IEEE J Sel Top Quant, 2010, 16, 1517.

4. C. Deibel and V. Dyakonov, Rep. Prog. Phys., 2010, 73, 096401.

5. S. D. Dimitrov and J. R. Durrant, Chem. Mater., 2013, 26, 616.

6. T. M. Clarke and J. R. Durrant, Chem. Rev., 2010, 110, 6736.

7. C. Deibel, T. Strobel and V. Dyakonov, Adv. Mater., 2010, 22, 4097.

8. T. M. Clarke, D. B. Rodovsky, A. A. Herzing, J. Peet, G. Dennler, D. DeLongchamp, C. Lungenschmied and A. J. Mozer, Adv. Energy Mater., 2011, 1, 1062.

9. M. A. Loi, S. Toffanin, M. Muccini, M. Forster, U. Scherf and M. Scharber, Adv. Funct. Mater., 2007, 17, 2111.

10. A. C. Morteani, P. Sreearunothai, L. M. Herz, R. H. Friend and C. Silva, Phys. Rev. Lett., 2004, 92, 247402.

11. L. Goris, K. Haenen, M. Nesladek, P. Wagner, D. Vanderzande, L. D. Schepper, J. D'Haen, L. Lutsen and J. V. Manca, J. Mater. Sci., 2005, 40, 1413

12. H. Ohkita, S. Cook, Y. Astuti, W. Duffy, S. Tierney, W. Zhang, M. Heeney, I. McCulloch, J. Nelson, D. D. C. Bradley and J. R. Durrant, J. Am. Chem. Soc., 2008, 130, 3030.

13. A. A. Bakulin, A. Rao, V. G. Pavelyev, P. H. M. van Loosdrecht, M. S. Pshenichnikov, D. Niedzialek, J. Cornil, D. Beljonne and R. H. Friend, Science, 2012, 335, 1340.

14. G. Grancini, M. Maiuri, D. Fazzi, A. Petrozza, H. J. Egelhaaf, D. Brida, G. Cerullo and G. Lanzani, Nat Mater, 2013, 12, 29.
15. K. Vandewal, S. Albrecht, E. T. Hoke, K. R. Graham, J. Widmer, J. D. Douglas, M. Schubert, W. R. Mateker, J. T. Bloking, G. F. Burkhard, A. Sellinger, J. M. J. Fréchet, A. Amassian, M. K. Riede, M. D. McGehee, D. Neher and A. Salleo, Nat Mater, 2014, 13, 63.

16. J. Lee, K. Vandewal, S. R. Yost, M. E. Bahlke, L. Goris, M. A. Baldo, J. V. Manca and T. V. Voorhis, J. Am. Chem. Soc., 2010, 132, 11878.

17. T. G. J. van der Hofstad, D. Di Nuzzo, M. van den Berg, R. A. J. Janssen and S. C. J. Meskers, Adv. Energy Mater., 2012, 2, 1095.

18. R. D. Pensack, K. M. Banyas and J. B. Asbury, IEEE J Sel Top Quant, 2010, 16, 1776.

19. S. Gélinas, O. Paré-Labrosse, C.-N. Brosseau, S. Albert-Seifried, C. R. McNeill, K. R. Kirov, I. A. Howard, R. Leonelli, R. H. Friend and C. Silva, J. Phys. Chem. C, 2011, 115, 7114.

20. F. Etzold, I. A. Howard, N. Forler, D. M. Cho, M. Meister, H. Mangold, J. Shu, M. R. Hansen, K. Müllen and F. Laquai, J. Am. Chem. Soc., 2012, 134, 10569.

21. F. Etzold, I. A. Howard, R. Mauer, M. Meister, T.-D. Kim, K.-S. Lee, N. S. Baek and F. Laquai, J. Am. Chem. Soc., 2011, 133, 9469.

22. I. A. Howard, R. Mauer, M. Meister and F. d. r. Laquai, J. Am. Chem. Soc., 2010, 132, 14866.

23. S. D. Dimitrov, A. A. Bakulin, C. B. Nielsen, B. C. Schroeder, J. Du, H. Bronstein, I. McCulloch, R. H. Friend and J. R. Durrant, J. Am. Chem. Soc., 2012, 134, 18189.

24. G. Grancini, N. Martino, M. R. Antognazza, M. Celebrano, H.-J. Egelhaaf and G. Lanzani, J. Phys. Chem. C, 2012, 116, 9838.

25. S. Yamamoto, H. Ohkita, H. Benten and S. Ito, J. Phys. Chem. C, 2012, 116, 14804.

26. D. Jarzab, F. Cordella, J. Gao, M. Scharber, H.-J. Egelhaaf and M. A. Loi, Adv. Energy Mater., 2011, 1, 604.

27. C. Piliego and M. A. Loi, J. Mater. Chem., 2012, 22, 4141.

28. M. C. Scharber, C. Lungenschmied, H.-J. Egelhaaf, G. Matt, M. Bednorz, T. Fromherz, J. Gao, D. Jarzab and M. A. Loi, Energ. Environ. Sci., 2011, 4, 5077.

29. M. Manca, C. Piliego, E. Wang, M. R. Andersson, A. Mura and M. A. Loi, J. Mater. Chem. A, 2013, 1, 7321.

30. M. Morana, H. Azimi, G. Dennler, H.-J. Egelhaaf, M. Scharber, K. Forberich, J. Hauch, R. Gaudiana, D. Waller, Z. Zhu, K. Hingerl, S. S. van Bavel, J. Loos and C. J. Brabec, Adv. Funct. Mater., 2010, 20, 1180.

31. J. Peet, J. Y. Kim, N. E. Coates, W. L. Ma, D. Moses, A. J. Heeger and G. C. Bazan, Nat. Mater., 2007, 6, 497.

32. J. T. Rogers, K. Schmidt, M. F. Toney, E. J. Kramer and G. C. Bazan, Adv. Mater., 2011, 23, 2284.

33. T. Clarke, A. Ballantyne, F. Jamieson, C. Brabec, J. Nelson and J. Durrant, Chem. Commun., 2009, 1, 89.

34. D. Di Nuzzo, A. Aguirre, M. Shahid, V. S. Gevaerts, S. C. J. Meskers and R. A. J. Janssen, Adv. Mater., 2010, 22, 4321.

35. D. J. D. Moet, M. Lenes, M. Morana, H. Azimi, C. J. Brabec and P. W. M. Blom, Appl. Phys. Lett., 2010, 96, 213506.

36. I.-W. Hwang, S. Cho, J. Y. Kim, K. Lee, N. E. Coates, D. Moses and A. J. Heeger, J. Appl. Phys., 2008, 104, 033706. 
37. M. Hallermann, E. D. Como, J. Feldmann, M. Izquierdo, S. Filippone, N. Martin, S. Juchter and E. v. Hauff, Appl. Phys. Lett., 2010, 97, 023301.

38. M. C. Scharber, M. Koppe, J. Gao, F. Cordella, M. A. Loi, P. Denk, M. Morana, H. J. Egelhaaf, K. Forberich, G. Dennler, R. Gaudiana, D. Waller, Z. G. Zhu, X. B. Shi and C. J. Brabec, Adv. Mater., 2010, 22, 367.

39. T. M. Clarke, J. Peet, P. Denk, G. Dennler, C. Lungenschmied and A. J. Mozer, Energ. Environ. Sci., 2012, 5, 5241.

40. J. Peet, L. Wen, P. Byrne, S. Rodman, K. Forberich, Y. Shao, N. Drolet, R. Gaudiana, G. Dennler and D. Waller, Appl. Phys. Lett., 2011, 98, 1.

41. D. H. K. Murthy, A. Melianas, Z. Tang, G. Juška, K. Arlauskas, F. Zhang, L. D. A. Siebbeles, O. Inganäs and T. J. Savenije, Adv. Funct. Mater., 2013, 23, 4262.

42. A. Kumar, S. Sista and Y. Yang, J. Appl. Phys., 2009, 105.

43. A. Wagenpfahl, D. Rauh, M. Binder, C. Deibel and V. Dyakonov, Phys. Rev. B, 2010, 82, 115306.

44. J. K. Lee, W. L. Ma, C. J. Brabec, J. Yuen, J. S. Moon, J. Y. Kim, K. Lee, G. C. Bazan and A. J. Heeger, J. Am. Chem. Soc., 2008, 130, 3619.

45. W. Li, Y. Zhou, B. Viktor Andersson, L. Mattias Andersson, Y. Thomann, C. Veit, K. Tvingstedt, R. Qin, Z. Bo, O. Inganäs, U. Würfel and F. Zhang, Org. Electron., 2011, 12, 1544.

46. T. J. Prosa, M. J. Winokur, J. Moulton, P. Smith and A. J. Heeger, Macromolecules, 1992, 25, 4364.

47. E. Verploegen, R. Mondal, C. J. Bettinger, S. Sok, M. F. Toney and Z. Bao, Adv. Funct. Mater., 2010, 20, 3519.

48. M. P. Eng, P. R. F. Barnes and J. R. Durrant, J. Phys. Chem. Lett., 2010, 1, 3096.

49. J. Guo, H. Ohkita, H. Benten and S. Ito, J. Am. Chem. Soc., 2009, 131, 16869.

50. J. Guo, H. Ohkita, S. Yokoya, H. Benten and S. Ito, J. Am. Chem. Soc., 2010, 132, 9631.

51. A. Ruseckas, M. Theander, M. R. Andersson, M. Svensson, M. Prato, O. Inganäs and V. Sundstrom, Chem. Phys. Lett., 2000, 322, 136.

52. A. Saeki, S. Seki, Y. Koizumi and S. Tagawa, J. Photochem. Photobiol. A: Chem., 2007, 186, 158.

53. S. Shoaee, M. P. Eng, E. Espildora, J. L. Delgado, B. Campo, N. Martin, D. Vanderzande and J. R. Durrant, Energ. Environ. Sci., 2010, 3, 971.

54. S. Subramaniyan, H. Xin, F. S. Kim, S. Shoaee, J. R. Durrant and S. A. Jenekhe, Adv. Energy Mater., 2011, 1, 854.

55. T. M. Clarke, A. Ballantyne, S. Shoaee, Y. W. Soon, W. Duffy, M. Heeney, I. McCulloch, J. Nelson and J. R. Durrant, Adv. Mater., 2010, 22, 5287.

56. T. M. Clarke, C. Lungenschmied, J. Peet, N. Drolet, K. Sunahara, A. Furube and A. J. Mozer, Adv. Energy Mater., 2013, 3, 1473.

57. T. M. Clarke, F. C. Jamieson and J. R. Durrant, J. Phys. Chem. C, 2009.

58. J. Nelson, Phys. Rev. B, 2003, 67, 155209.
59. I. Montanari, A. F. Nogueira, J. Nelson, J. R. Durrant, C. Winder, M. A. Loi, N. S. Sariciftci and C. Brabec., Appl. Phys. Lett., 2002, 81, 3001.

60. A. F. Nogueira, I. Montanari, J. Nelson, J. R. Durrant, C. Winder, N. S. Sariciftci and C. Brabec, J. Phys. Chem. B, 2003, 107, 1567.

61. Y. Kim, S. Cook, S. M. Tuladhar, S. A. Choulis, J. Nelson, J. R. Durrant, D. D. C. Bradley, M. Giles, I. Mcculloch, C.-S. Ha and M. Ree, Nat. Mater., 2006, 5, 197.

62. D. Veldman, O. Opek, S. C. J. Meskers, J. Sweelssen, M. M. Koetse, S. C. Veenstra, J. M. Kroon, S. S. v. Bavel, J. Loos and R. A. J. Janssen, J. Am. Chem. Soc., 2008, 130, 7721.

63. S. Yamamoto, H. Ohkita, H. Benten, S. Ito, S. Yamamoto, D. Kitazawa and J. Tsukamoto, J. Phys. Chem. C, 2013, 117, 11514. 